\title{
FIVE CASES OF CONGENITAL LUNG CYST
}

\author{
BY \\ G. B. FLEMING, B.A., M.D. \\ (From the Department of Paediatrics, Glasgow University and the Royal \\ Hospital for Sick Children, Glasgow.)
}

More than 150 cases of congenital lung cyst have been reported in the literature. In the majority the cysts were multiple and only about 14 cases have been described in which a large single cyst was present. There is considerable diversity of opinion regarding the aetiology of the condition. Some have attributed it to developmental abnormalities such as faulty development of the lymph vessels of the corresponding lung lobes leading to hydropic cystic formation (Grawitz') or defective development of alveoli with widening of bronchi ${ }^{2}$, some to congenital atelectasis ${ }^{3}$ and some to inflammatory processes such as bronchopneumonia ${ }^{4,5}$ or congenital syphilis. Koontz ${ }^{6}$ describes a case in which there was narrowing of the smaller bronchi from over-growth of the lung epithelium with dilatation of the bronchial system distal to the obstruction. It appears, therefore, that some attribute the condition to congenital maldevelopment and others to disease affecting the lung or bronchi either in utero or after birth. It is probable that in most of the cases the cysts derive their origin from bronchial or atrial tissue.

Histologically the walls of the cysts have usually been found to be lined with columnar or cuboidal epithelium and the walls to contain unstriped muscle, elastic and fibrous tissue and sometimes cartilage. In some cases flattened epithelium has been found. In a case reported by de Lange $^{2}$ in which there were numerous cysts, the smallest were lined by cylindrical epithelium, the larger by cuboidal or flat epithelium and in the largest the walls were almost completely denuded of epithelium. Stewart, Kennedy and James $^{7}$ reported similar findings in their case of multiple cysts. The presence of flattened epithelium does not necessarily exclude the possibility of a cyst being derived from bronchial or atrial tissue for the nature of the epithelial lining may be profoundly modified by ballooning of the walls of the cyst and by the presence of infection.

Koontz ${ }^{6}$ has collected the cases recorded up to 1925 and discussed the aetiology, and Anspach and Wolman have added 2 additional cases of solitary cyst and reviewed the literature up to 1932. Since then I have been able to find reports of 5 cases of solitary cyst. Three contained air $^{9,10,11}$, one fluid and air (Croswell and King ${ }^{12}$ ) and one pus $\left(\mathrm{Zarfl}^{13}\right)$. Three died but in only one was there a post-mortem examination (Gammon and Mallory ${ }^{10}$ ). In this case the cyst, which contained air and was connected with a bronchus by a small opening, had ruptured into the pleura. The wall of the cyst was trabeculated and was denuded of epithelial lining. The case 
reported by Zarfl was thought by him to be a large abscess cavity but it was probably an infected cyst. Anspach and Wolman ${ }^{8}$ have suggested a classification which is based on the assumption that congenital embryonic malformation is the primary cause. This leads either to the formation of a solitary or to multiple cysts; in either case the cysts at first contain fluid. In the solitary cyst, if there is no communication with a bronchus, the fluid persists but if a free opening occurs a non-expansile, air-containing cyst results, while if the opening is valved an expansile balloon cyst develops. Multiple cysts may also empty themselves and become inflated with air and either form multiple air-containing cysts or, if the walls dividing them one from another break down, a single trabeculated cyst. In one of the cases described by Anspach and Wolman the cyst when first seen contained air and fluid; eventually the fluid was coughed up and the cyst became filled with air only. Swanson, Platou and Sadler ${ }^{14}$ have reported a case in which the cyst contained fluid only while in the cases described by Croswell and King ${ }^{12}$, and Parmelee and Apfelbach ${ }^{15}$ air and pus were present. The contents of the cysts, therefore, seem to depend on whether there is a connection with a bronchus and whether infection has occurred.

The recognition of multiple cysts during life is often difficult. As a rule the condition when uncomplicated causes only slight symptoms of cyanosis and dyspnoea and the presence of the cysts may only be discovered for the first time at post-mortem examination. Radiography has done much to bring this peculiar condition to light during life. Without its help it is usually impossible to make a diagnosis of multiple cysts. Stewart, Kennedy and $\mathrm{James}^{7}$ noted a sound heard on auscultation indistinguishable from pleural friction which they suggest may be of diagnostic value. Single cysts may be of sufficient size to give signs closely resembling pneumothorax. In these cases the heart may be displaced and there is usually a hyper-resonant percussion note all over the affected side with great diminution of respiratory murmur. The coin sign is absent. In young infants there may be severe respiratory distress which can generally be relieved by aspirating the air through the chest wall. The radiogram may present a picture indistinguishable from pneumothorax though Debré and Blinder ${ }^{11}$ consider that the absence of a shadow representing the root of the lung is of diagnostic value. In some cases a linear shadow thrown by the wall of the cyst can be seen.

The differentiation of lung cyst from pneumothorax is of importance to prognosis and treatment. In the latter a serious lung lesion is almost always present while in the former the remaining lung tissue may be normal and except for diminution in lung area and interference with respiration from the size of the cyst there may be no disability. Two of the present series of cases exemplify this. For this reason in cases where there are physical signs and a radiographic picture of pneumothorax without a definite lung lesion the presence of a cyst should be suspected.

The following five cases are all examples of the single cyst. In four of these the cysts contained air and in one fluid. Three of the children died, while two are still alive and apparently healthy. In one of the fatal cases 
the presence of the cyst was probably of small consequence. The child died of bronchopneumonia and at autopsy the cyst found was probably not of sufficient size seriously to have interfered with respiration. In the other two fatal cases the cysts were of such magnitude that they in all probability caused grave respiratory embarrassment; in one of them this appeared to be the cause of death, while in the other bronchopneumonia complicated the picture and was probably the cause of death, though from the history there was some degree of respiratory embarrassment before the onset of the fatal illness.

\section{Case reports.}

Case 1.-F. H., male, aged 6 months, was admitted to Dr. Findlay's wards on 25.7.21. He was a fourth child, and an elder brother died of a ' fit' at the age of 10 months. Labour was normal. The baby was healthy at birth and did well until 6 weeks before admission when he became short of breath and ceased to thrive.

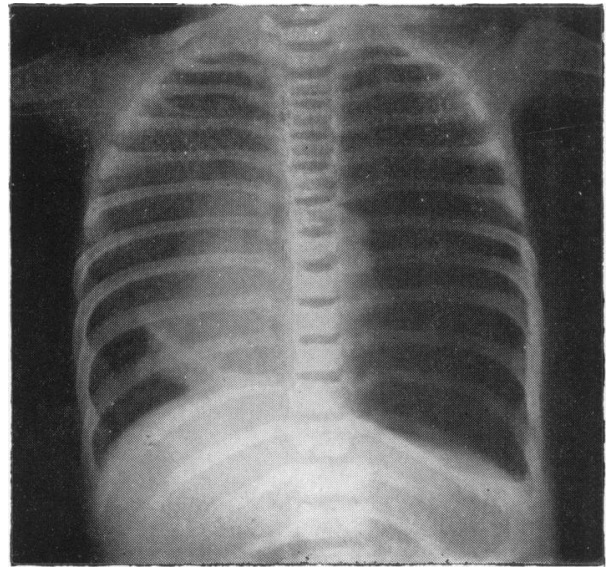

FIg. 1. Case 1. Showing cyst occupying the whole of the left side of the chest, the heart displaced to the right side and the shadow of the wall of the cyst overlying the pericardium.

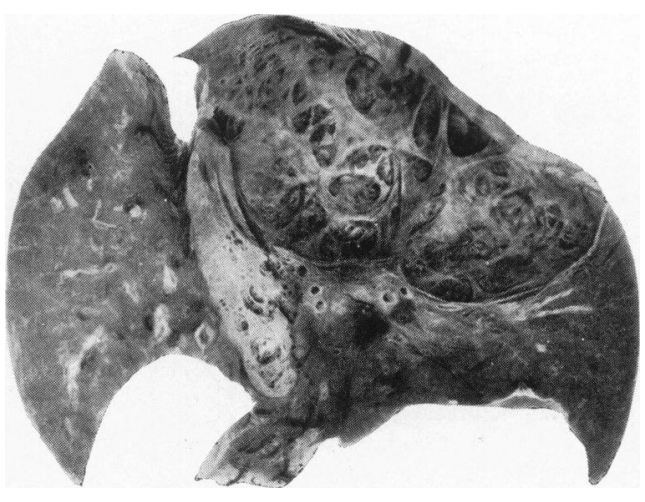

FIg. 2. Case 1. Vertical section of left lung showing large cyst with reticulated wall in upper and outer part of lower lobe. Emphysematous area in upper and medial part of lower lobe- $\times \frac{3}{4}$.

On admission his weight was $4.77 \mathrm{kgm}$. He was cyanosed, with a respiration rate of 44 per minute. No cardiac dulness could be detected and the heart sounds were inaudible except in the epigastrium. There was bulging in front and flattening of back of left side of chest. A tympanitic note was present all over the' left side of chest. The respiratory murmur was very defective on the left side and harsh on the right side with some râles at right base. No coin sign was found. The Pirquet test was negative.

On day of admission the child became very cyanosed and dyspnoeic and looked like dying. The left side of chest was explored and air under slight pressure withdrawn. This gave immediate relief. During the ten weeks the child was in hospital he did not thrive. The respiration rate was always rapid and there were occasional febrile attacks. On four occasions the child became very cyanosed and extremely distressed. On the first three of these relief was obtained after withdrawing air from the left side of the chest but on the last he was not relieved and died 1 hour later.

Skiagrams showed abnormal transparency of the left side of the chest with lung markings only visible at the base (fig. 1). The left side of the diaphragm was depressed and the heart shadow was almost completely displaced to the right 
side. On the right side overlapping the heart shadow there was a dense band possibly representing the part of the wall of the cyst overlapping the pericardium.

Post-mortem examination. On opening the thoracic cavity a large sac-like structure containing air was found covering the pericardium and the structures in the anterior and superior mediastina. Laterally it extended into the left pleural cavity and completely hid from view the left lung which was collapsed but it did not encroach on the right pleural cavity to any extent. The condition was not one of pneumothorax as the air was contained in the sac-like structure just described and not in the pleural sac. Along the middle line the air-containing sac was firmly attached to the anterior surface of the pericardium and to the tissues immediately above this, while laterally it blended with the anterior margin of the lower lobe of the collapsed left lung. Otherwise it showed no attachment to the walls or contents of the thoracic cavity. The wall of the sac was thin and contained a plentiful blood supply (as viewed by transmitted light). In its lower part, in the region of the diaphragm, there was a thickening of the sac wall which had all the appearance of an isolated portion of emphysematous lung tissue.

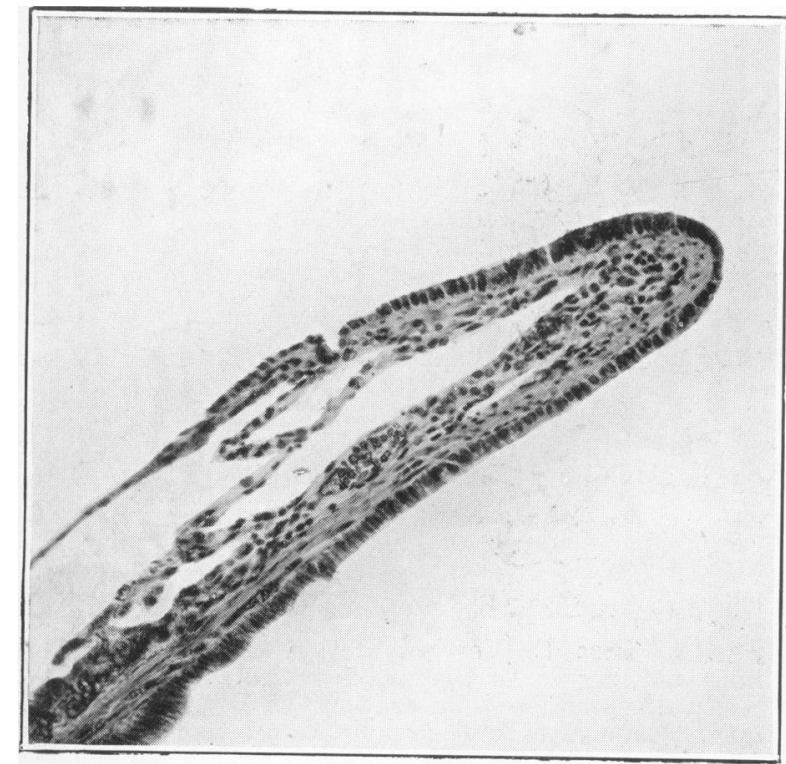

FI(. 3. Case 1. Portion of wall of cyst showing lining of typical columnar ciliated cells and transition to cuboidal and flattened epithelium; sub-epithelial layer of non-striped muscle. Haematoxylin and $\operatorname{eosin}-\times 200$.

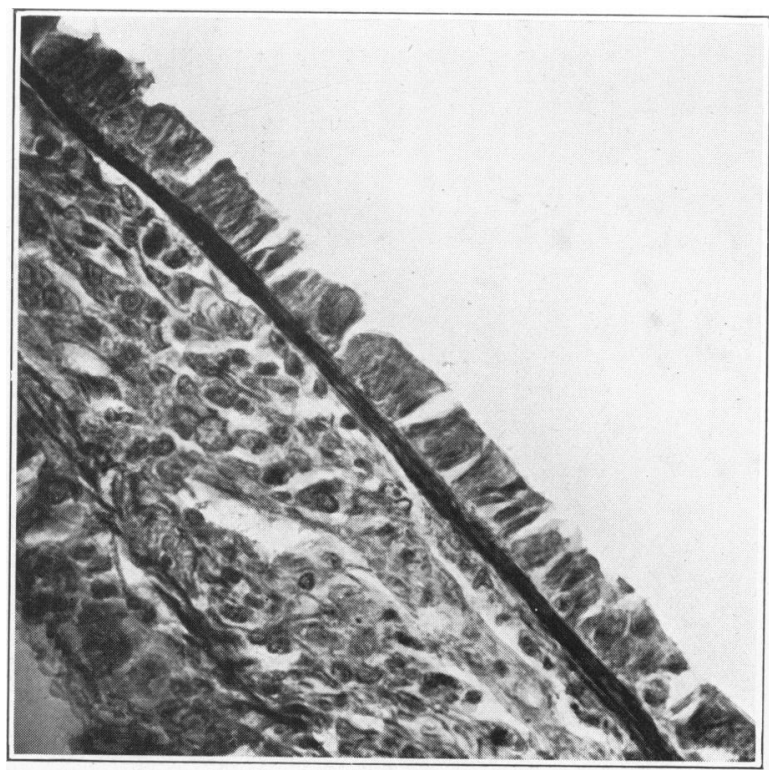

FIG. 4. Case 1. Columnar ciliated cells and occasional goblet cells lining cyst. Sub-epithelial layer of elastic fibres. Weigert's elastic stain and haematoxylin $-\times 400$.

Experimentally it was found that the sac could be inflated through the left bronchus, the detached portion of lung described above ballooning first and being followed by a gradual distension of the large sac itself. Deflation took place very slowly. On opening the sac it was found to be transversed by numerous delicate fibrous trabeculae (fig. 2). The left lung was collasped and no part of it appeared to be air-containing except the detached portion described above. The right lung, apart from very marked emphysema, was healthy in appearance. Except for emphysema of the right lung and hypertrophy of the right ventricle the other organs appeared healthy.

Histology. For the most part the lining of the cyst was composed of typical columnar ciliated epithelium with scanty goblet cells. At places transition from the columnar through cuboidal to flattened epithelium could be seen (fig. 3). The sub-epithelial tissues consisted of a fine layer of unstriped muscular fibres in addition to bundles of well formed elastic tissue (fig. 4.). This musculo-elastic 
layer was continuous around the whole cyst though it varied in thickness. Serial sections of the lung side of the cyst showed a communication with the bronchial system through a much distended atrial passage.

This case is a typical example of the single air containing cyst arising from bronchial tissue. The fact shown at autopsy that air only escaped from it very slowly undoubtedly accounted for its large size and the symptoms of respiratory embarrassment.

Case 2.-J. T., male, aged 3 weeks, was an eighth child, all the other children being alive and well, except for the fourth who died of measles and bronchopneumonia at the age of $1 \frac{1}{2}$ years. The labour was normal and the child appeared healthy at birth. Since then there had been attacks of dyspnoea. When he was 8 days old the mother noticed increased difficulty in breathing and dilatation of the alae nasi. This persisted and at times the child had severe attacks of dyspnoea and cyanosis.

On admission to Dr. Findlay's wards the child weighed $3.7 \mathrm{kgm}$. and appeared healthy except for slight cyanosis and laboured respiration. The heart was not notably displaced and the sounds were normal. The percussion note was hyper-resonant on

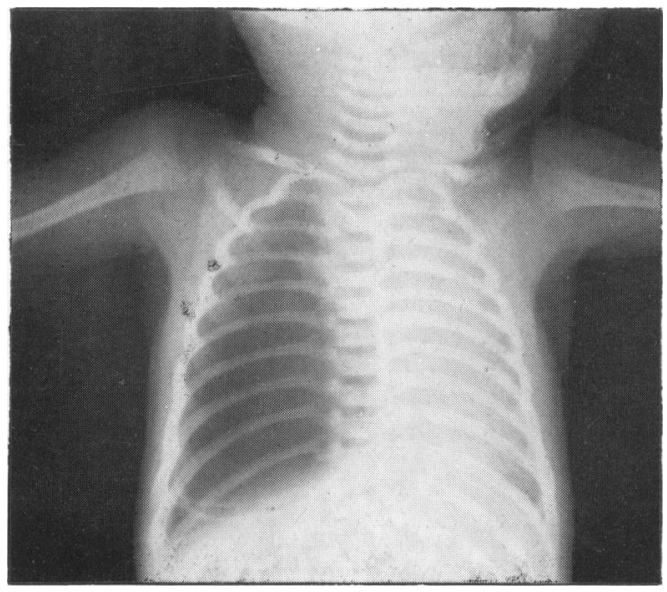

Fig. 5. Case 2. Showing cyst of the right lung. The shadow of the wall of the cyst can be seen in the lower part of the chest.

the right side in front and behind there was dull tympany. On the left side the note was impaired in front. The respiratory murmur was very defective all over the right side but well heard on the left side. The liver was palpable two finger breadths below the costal margin. The other organs appeared normal. A Pirquet reaction was negative.

The child had numerous attacks of dyspnoea with great cyanosis. He was afebrile thoughout. On two occasions during attacks of dyspnoea the chest was explored and air escaped under considerable pressure. This gave immediate relief to the cyanosis and dyspnoea. The child died two days after admission to hospital.

Skiagrams of the chest showed a large clear area on the right side extending downwards from the level of the fourth rib to the base but not encroaching on the right complemental pleural space. The right side of the diaphragm was depressed. The clear area was surrounded by a linear shadow. Lung tissue was visible at the right apex and at the base. The mediastinum was displaced to the left. There was dense consolidation of the greater part of the left lung (fig. 5). 
In this case the $\mathrm{x}$-ray picture gives the clue to the nature of the condition. In it the wall of the cyst can be clearly seen. This and the evidence of lung tissue at the apex and base make it almost certain that the condition was one of cyst of the lung and not pneumothorax. Unfortunately, as no postmortem examination could be made it is impossible to determine the origin of the cyst. The consolidation of the left lung was probably the cause of death.

Case 3.-N. McG., male, aged 41 weeks, was a first child, healthy at birth who did well until 2 days before admission to hospital when he became fevered and respirations became distressed and noisy.

On admission to Dr. Findlay's wards the child was found to be well nourished (weight $8.1 \mathrm{kgm}$.) but acutely ill. There was impaired percussion note all over

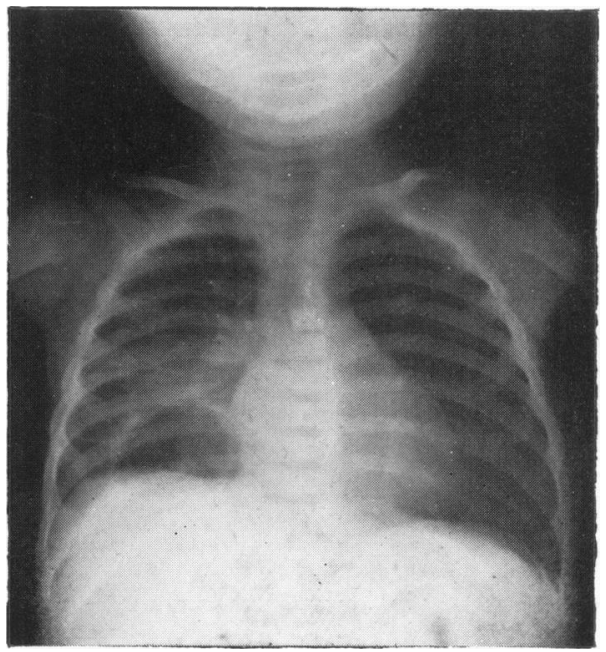

Fig. 6. Case 3. Showing the cyst in the lower part of the right side of the chest.

the right side of the back of the chest and tubular breathing at the right scapular angle. There was copious albumin in urine. The temperature was $104^{\circ}$ and a Pirquet reaction was positive.

The temperature remained high for 2 weeks and then gradually came down to normal by the end of the fourth week in hospital. A week later it began to rise again and the child developed, signs of fluid at the right base. On exploration of the chest 5 c.c. of turbid fluid were withdrawn containing many polymorphonuclear leucocytes and yielding a scanty growth of pneumococcus. The fever continued and the child died 8 weeks after admission to hospital.

Skiagrams taken 17 days before death showed a thin layer of fluid and a picture suggestive of cavitation at the right base. Between this and the consolidated right lung the shadow of the wall of the cyst can be seen (fig. 6).

At the post-mortem examination bronchopneumonia of the lower and upper lohes of the right lung was found. In the middle lobe near the hilum there was is cystic structure about the size of a walnut protruding from the pleura much like 
an emphysematous bulla. The cyst contained air and the walls were smooth. It did not appear to have any relation to bronchi. The kidneys showed cloudy swelling.

HIstology. Only at places had the cyst any epithelial lining; this consisted of a flattened type of epithelium with prominent deeply staining nuclei. The subepithelial tissues were composed of irregular strands of fibrous tissue in which a few elastic fibres were irregularly distributed. No unstriped muscle was present. In addition there was much inflammatory cellular infiltration in the wall of the cyst due to the spread of an inflammatory process from neighbouring lung tissue (fig. 7).

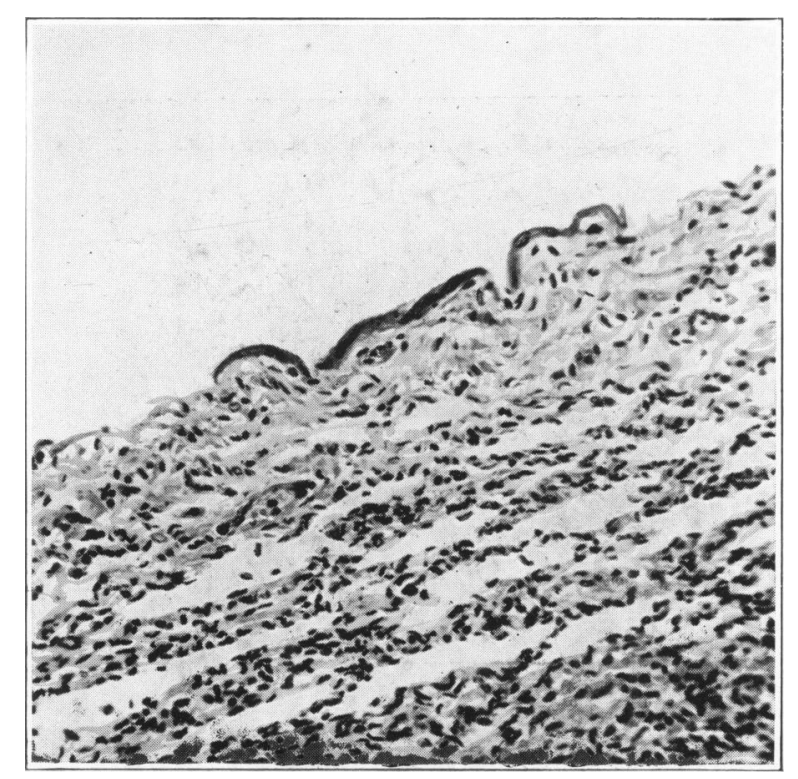

Fig. 7. Case 3. Large flattened degenerating cells lining cyst; sub-epithelial connective tissue with inflammatory cellular infiltration; acute interstitial cellular infiltration of underlying lung. Haematoxylin and eosin- -200 .

The cyst in this case was probably not of the expansile type though as it contained air it must have had some connection with the bronchial system. From the histological findings it would appear that it did not owe its origin to bronchial or atrial tissue and may have been of lymphangiectatic origin. The coincident inflammatory condition of the surrounding lung may, however, have altered the histological structure of its wall and lining.

Case 4.-J. McN., male, aged 8 months, was an only child. His parents were healthy and the family history was not relevant. He was a normal full-time infant and breathed immediately after birth and progressed satisfactorily. He was breast 
fed for 6 weeks. At age of 4 months, the child developed a cough and at that time his doctor noticed dulness and absence of respiratory murmur over the whole of the right side of the back of the chest. This persisted until admission. The child had occasional attacks of respiratory distress and cough.

On admission to hospital on 24.4.33, the child appeared healthy except for a moderate degree of scoliosis. His weight was $6.6 \mathrm{kgm}$. The heart was not displaced and the sounds were normal. Slight bulging of the right side of back of chest was noted. There was a dull area at the left apex which merged with the cardiac dulness. The percussion note in the left axilla, lateral region and over the left side of back was clear. On the right side it was dull from level of fourth rib in the nipple line to costal margin. Behind it was dull all over the right side. The respiratory murmur was harsh but well heard all over the left side. On the right side the respiratory murmur was rather harsh in front and very defective all over the back. The lower border of the liver was two finger breadths below the costal

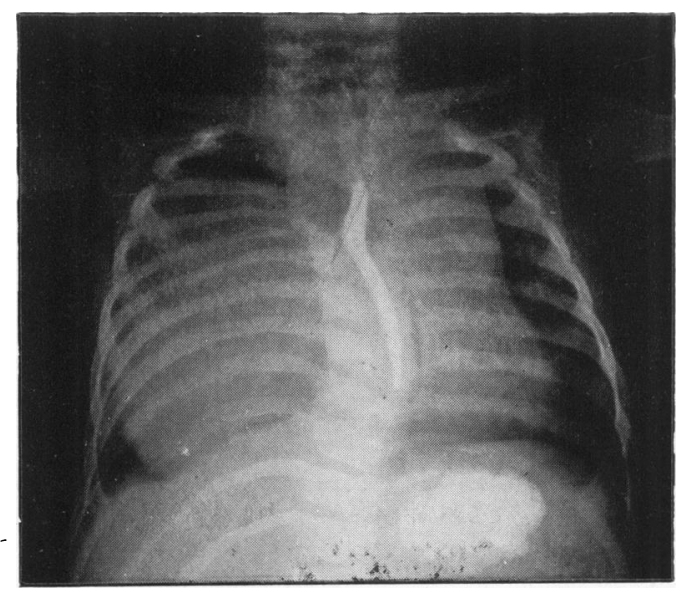

Fig. 8. Case 4. Showing fluid containing cyst in right lung, deformity of thoracic vertebrae and displacement of the mediastinum to the left. There is barium in the oesophagus and stomach.

margin. The Mantoux tuberculin test was negative. The child remained perfectly well thoughout his stay in hospital. The right chest was explored on four occasions. On the first occasion 25 c.c. of colourless slightly milky fluid were withdrawn; the last few c,c. were blood stained. On three subsequent occasions 135 c.c., 150 c.c. and 70 c.c. respectively were withdrawn; on each occasion the dulness on the right side diminished and the respiratory murmur became fuller. Histological examination of the fluid revealed ciliated columnar epithelial and goblet cells.

The child was last seen at the age of $1 \frac{1}{4}$ years when he seemed perfectly healthy. The physical signs in the chest were unchanged. He is now 2 years old and his doctor reports that he is a healthy well-nourished child.

Skiagrams of the chest showed a dense circular shadow on the right side extending from the level of the second rib to the base (fig. 8). The mediastinum was displaced to the left and there was a deformity of the upper seven thoracic vertebrae. A skiagram taken shortly after paracentesis showed collapse 
of the cyst and expansion of the right lung (fig. 9) while a skiagram taken some days later showed the cyst to have refilled. In lateral views the cyst is seen to occupy the posterior part of the chest.

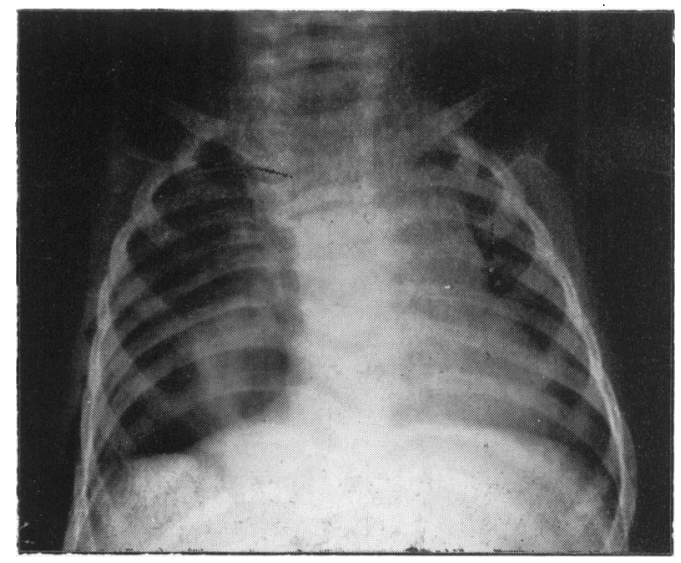

Fig. 9. Case 4. Skiagram after fluid had been withdrawn from the cyst.

This case shows the condition before connection with a bronchus had occurred. It is possible that the cyst may empty itself at some future date and, if the bronchial opening happens to be valved, a state of affairs similar to that of cases 1, 2 and 5 may arise. If, on the other hand, there is free egress of air from the cyst it may gradually disappear.

The significance of the deformity of the dorsal vertebrae is difficult to assess. It might be supposed that the cyst owed its origin to mesodermal tissue connected with the vertebrae but the fact that it contains bronchial epithelium is convincing evidence that it has arisen from some part of the bronchial system.

Case 5.-J. Q., female, aged 8 years, was admitted to hospital on 8.11.33. She was the third child, two elder children being healthy. A younger brother had died aet. 9 months of congenital heart disease and rickets. At birth the child appeared healthy and breathed immediately: there was no cyanosis. She was breast-fed for 14 months and developed normally. She always seemed healthy except for measles at 2 years from which she made a good recovery. Five days before admission to hospital she had a sudden severe attack of pain in left side; this gradually abated and child seemed well in two days. She was sent to hospital because the doctor noticed that the heart's impulse was on the right side of the chest.

On admission the child appeared quite comfortable with a slightly dusky colour. There was no dyspnoea and no clubbing. She was pigeon-chested. The apex beat was 3 inches to right of sternum in fifth space. No cardiac dulness could be detected. The heart sounds were normal and were better heard to right of sternum than to the left. The movements of the chest were fuller on right side than on left. Hyper-resonance was present all over the left side where respiratory murmur was very defective. The coin sound was well heard on the left side. The spleen was palpable one finger breadth below the costal margin. Both sides of the diaphragm were acting. The Mantoux tuberculin test was negative. The chest was explored on Nov. 16 and 600 c.c. of air withdrawn, not under notable pressure. One day later the coin sound could not be elicited though the other signs of pneumotherax persisted. Throughout her residence in hospital the child appeared quite healthy 
and when last seen on April 25, 1934, seemed perfectly well except for slight cyanosis. The physical signs were unchanged.

Skiagrams taken on the day after admission showed abnormal transparency of the greater part of the left side of the chest, extending across the middle line in the upper mediastinum. At the region of the root of the left lung there was a tongue-like shadow extending obliquely downwards and outwards to the left and at the extreme base there were some indications of lung tissue. In the lower part of

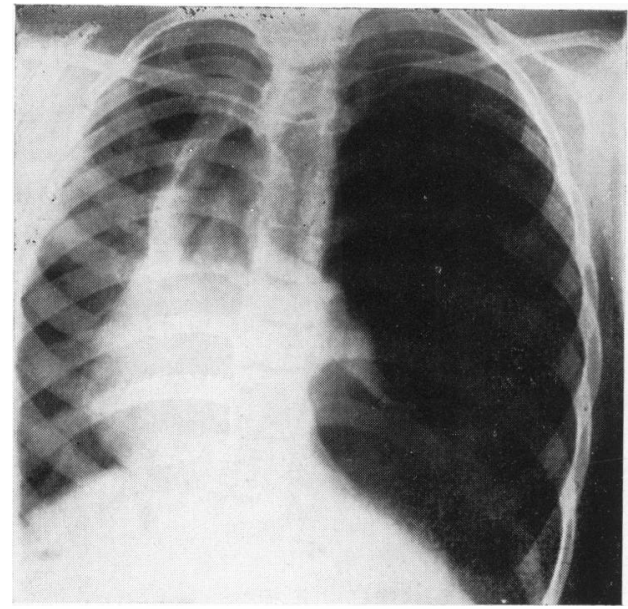

FIg. 10. Case 5. Showing pneumothorax of left side and a tongue of opaque tissue extending outwards and downwards from the region of the hilum. The heart and mediastinum are displaced to the right.

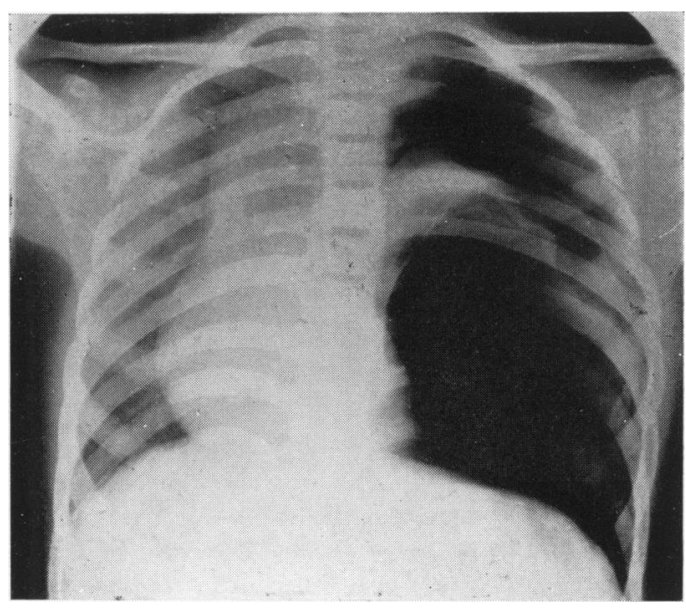

FIg. 11. Case 5. Showing the cyst partially expanded and a small portion of lung resting on its upper surface.

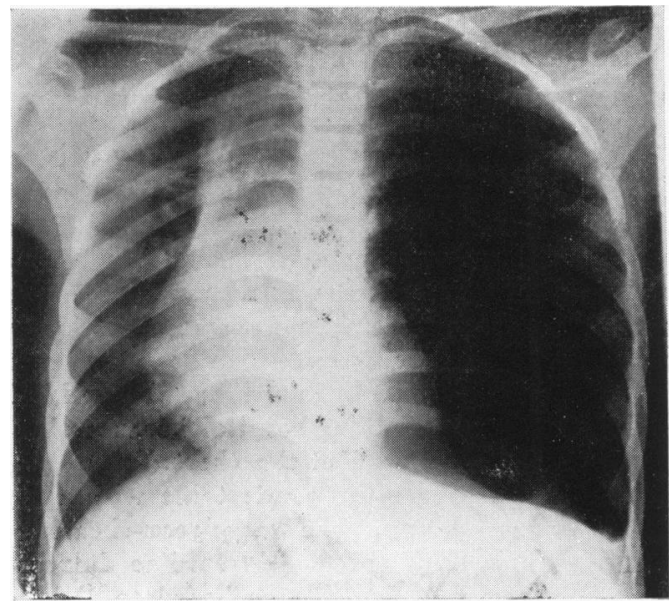

Fig. 12. Case 5. Showing the cyst completely expanded.

the left side a linear shadow could be seen probably representing the wall of the collapsed cyst. The heart and mediastinum were displaced to the right (fig. 10). Skiagrams taken after the withdrawal of air from the pleura showed the cyst in various stages of expansion and the tongue of tissue, seen in the first films projecting from the hilum, was seen resting on the upper surface of the cyst (fig. 11 and 12). 
Skiagram taken after intratracheal injection of lipiodol showed the left bronchus twisted upwards in a sharp curve and a small amount of the opaque oil in the upper part of the chest but none in the cyst.

This patient is of interest because she was thought to be a perfectly healthy child until the spontaneous rupture of the cyst into the pleura caused some transient pain but little constitutional disturbance. Apart from this illness the child appeared to be perfectly healthy in spite of the fact that only one lung was functioning and that the heart was completely displaced to the right side of the chest. Had it not been for the occurrence of rupture of the cyst the condition might never have been discovered.

Gammon and Mallory ${ }^{10}$ have reported a similar case of spontaneous rupture of a large air containing cyst into the pleura in a child of 15 months. The child died, probably of bronchopneumonia.

The early skiagrams of our patient showed the collapsed portion of the upper lung lobe lying in the region of the hilum. With expansion of the cyst the fragment of lung also expanded and later skiagrams showed it at the apex resting on the dome of the cyst. The presence of a root shadow at the time when there was a true pneumothorax and its disappearance with the expansion of the cyst and the absorption of air from the pleura is in agreement with the suggestion of Debré and Blinder ${ }^{11}$ that in lung cyst a shadow representing the root of the lung is not seen in the radiogram.

It is impossible to determine the origin of the cyst in this case but the physical signs and radiographic picture are very similar, on a larger scale, to those presented by case 1 which we know to have been of bronchial origin.

\section{Discussion.}

In three of these cases there were physical signs of pneumothorax and indeed, in one of them a true pneumothorax from rupture of the cyst wall actually existed, but in none was there any antecedent pulmonary lesion which could account for the condition. Debré and Blinder ${ }^{11}$ have reported the case of a boy of 15 years with a large cyst of the right lung who though apparently healthy, except for signs of pneumothorax, had been treated for pulmonary tuberculosis since the age of 6 years. It would seem, therefore, that in a child with signs of pneumothorax without a lung lesion to account for the condition, cyst of the lung should be suspected. The radiographic evidence is of great assistance in arriving at a diagnosis. Frequently the wall of the cyst can be demonstrated and evidence of lung tissue at the apex and base can be seen.

In cases 1 and 4 the presence of columnar ciliated epithelium shows that the cysts owed their origin to bronchial tissue and in case 3, though only flattened epithelium was found in the wall of the cyst, the inflammatory process in which the cyst was involved may have modified its epithelial lining.

The treatment must depend on the age of the child and the degree of respiratory embarrassment. In young infants probably all that can be done is to relieve pressure by withdrawal of air from the cyst by paracentesis. 
In two of our cases this gave immediate though temporary relief. Two cases have been reported in which obliteration of the cyst was achieved by injection of irritating substances into the cavity of the cyst. Croswell and King $^{12}$ injected iodised poppy seed oil in one case (a child aged 3. years) and after a sharp reaction the cyst collapsed and the lung expanded. A fluidcontaining cyst, in a child aged 10 weeks, was treated by injection of formaldehyde solution by Swanson, Platou and Sadler ${ }^{14}$. This caused great diminution in the size of the cyst but unfortunately the child died later after a bronchoscopic examination. Case 4 of the present series is very similar to the one described by Swanson, Platou and Sadler but, as the cyst does not seem to be interfering in any way with the child's well-being, any attempt to abolish it does not at present seem to be justified.

In case 5 there appears to be so little functioning tissue of the left lung that extirpation of the cyst would do little more than cause collapse of the left side of the chest without improving the respiratory function.

\section{Summary.}

1. Five cases of single lung cyst are described.

2. In four the cysts contained air; in one fluid.

3. The cyst in one case was lined by columnar ciliated epithelium and in another by flattened epithelium. Ciliated epithelial cells were detected in the fluid withdrawn from the fluid-containing cyst.

4. Three of the patients died; two are alive and apparently well.

5. In two of the cases in which there were signs of respiratory embarrassment paracentesis and withdrawal of air relieved the symptoms temporarily.

I have much pleasure in expressing my thanks to Dr. Leonard Findlay for permission to make use of his case records, to Dr. Blacklock for the pathological reports and to Dr. Suttie for the radiograms.

\section{REFERENCES.}

1. Grawitz, P., Virchows Arch. f. path. Anat., Berlin, 1880, LXXXII, 217.

2. de Lange, C., Acta paediat., Uppsala, 1927, VI, 352.

3. Francke, W., Deutsches. Arch. f. klin. Med., Leipzig, 1894, LII, 124.

4. Box, C. R., Lancet, London, 1907, i, 16.

5. Kanthack, A. A., \& Rolleston, H. D., Trans. Path. Soc. Lond., London, 1897, XLVIII, 32.

6. Koontz, A. R., Bull. Johns Hopkins Hosp., Baltimore, 1925, XXXVII, 340.

7. Stewart, H. L., Kennedy, P. J., \& James, A. E., Arch. Path., Chicago, 1932, XIV, 625.

8. Anspach, W. E., \& Wolman, I. J., Surg. Gynec. \& Obst., Chicago, 1933, LVI, 635.

9. Chabrun, J., \& Joseph, E., Bull. Soc. de pédiat. de Paris, Paris, 1932, XXX, 19.

10. Gammon, W. N., \& Mallory, T. B., New Eng. J. Med., Boston, 1932, CCVII, 148.

11. Debré, R., \& Blinder, H., Bull. et mém. Soc. de méd. d. hôp. de Paris, Paris, 1932, XIX, 818.

12. Croswell, C. V., \& King, J. C., J. Am. Med. Ass., Chicago, 1933, CI, 832.

13. Zarfl, M., Ztschr. f. Kinderh., Berlin, 1933, LIV, 94.

14. Swanson, W. W., Platou, E. S., \& Sadler, W., Am. J. Dis. Child., Chicago, 1928, XXXV, 1024.

15. Parmelee, A. H., \& Apfelbach, C. W., ibid, 1931, XLI, 1380. 